\title{
Desenvolvimento de novas competências e práticas de gestão da inovação voltadas para o desenvolvimento sustentável: estudo exploratório da Natura
}

\author{
Anapatrícia Morales Vilha * \\ Ruy de Quadros Carvalho **
}

\section{Resumo}

A preocupação com a questão ambiental tem levado o setor produtivo a desenvolver tecnologias e práticas produtivas menos poluentes e orientadas para a conservação do meio ambiente, gerando crescentes oportunidades de negócios a partir de inovações voltadas para a produção sustentável. Este artigo pretende analisar as implicações que a busca de uma trajetória baseada em tecnologias e produtos sustentáveis traz para o processo de gestão da inovação e para 0 acúmulo de competências a ele associadas. Para isso, o texto explora o caso da Natura, uma empresa brasileira do setor de cosméticos. Os autores valeram-se da coleta de dados secundários, sobre a empresa e seu setor de atuação, e de dados primários, sobre temas de ordem estratégica e marketing, conseguidos durante entrevistas com profissionais dessa empresa e que atuam na área de pesquisa e desenvolvimento (P\&D). Os resultados mostram que a Natura tem sido capaz de perceber as oportunidades tecnológicas e de mercado, ao desenvolver produtos voltados para nichos de mercado ainda não explorados. Revelam também que está apta para o esforço de implementação, nada trivial, de rotinas inteiramente novas, como também de mobilizar recursos e competências no seu processo de gestão da inovação tecnológica.

Palavras- chave: Estratégias empresariais sustentáveis; gestão da inovação tecnológica; produtos da biodiversidade.

\begin{abstract}
Environment issues have induced firms to search and develop cleaner technologies and production practices. This process has created new business opportunities that are related to sustainable production and to the conservation of the environment. This paper aims at understanding the implications of innovation trajectories based on the development of sustainable products and technologies for innovation management practices and the related managerial competencies. The study explores the case of a Brazilian leading cosmetic manufacturer - Natura through secondary data of the company and its industry; and primary data by means of interviews with professionals of the research and development, strategy and marketing areas of Natura. The results show that the company presents a capability of perception of the technological and market opportunities when developing products for market niches not explored, besides the effort for implementating routines entirely new for the company and the mobilization of resources and competencies in its technological innovation management.
\end{abstract}

Key words: Sustainable business strategies; technological innovation management; products from biodiversity.

\footnotetext{
* Pesquisadora do Grupo de Estudos de Empresas e Inovação - GEMPI(DPCT/IG/UNICAMP). E- mail: Ana@ ige.unicamp.br. Endereço: Rua João Pandiá Calógeras, 51 Cidade Universitária / Distrito Barão Geraldo / Instituto de Geociências - Departamento de Política Científica e Tecnológica / Campinas. São Paulo-SP. CEP: 13.083970.

** Professor Livre Docente do Departamento de Política Científica e Tecnológica / Instituto de Geociências. Coordenador do Grupo de Estudos de Empresas e Inovação - GEMPI (DPCT/IG/UNICAMP). E- mail: ruyqc@ ige.unicamp.br. Endereço: Rua João Pandiá Calógeras, 51 - Cidade Universitária / Distrito Barão Geraldo / Instituto de Geociências - Departamento de Política Científica e Tecnológica / Campinas. São Paulo- SP. CEP: 13.083-970. Artigo aceito para publicação em novembro de 2004 e aceito em março de 2005.
} 


\section{Introdução}

Nas últimas décadas, verificou-se em todo o mundo uma preocupação crescente com as questões ambientais, em decorrência principalmente da degradação do meio ambiente e das práticas não-sustentáveis de uso dos recursos naturais, que acarretam perda da diversidade ambiental nos ecossistemas. A relação entre empresas e meio ambiente sempre foi complexa e alvo de controvérsias, além de ser objeto de discussões em nível mundial pelos chamados "plurinteressados" (sociedade, governo, articulações de órgãos internacionais e a concorrência) que direta e indiretamente atuam nesse debate (ROBBINS, 2001).

A questão ambiental - ao tornar o setor produtivo mais suscetível aos problemas ecológicos - possibilitou oportunidades de negócios baseadas em inovações voltadas para a produção sustentável (CORAZZA, 1996). Embora isso seja recente e ocorra de modo incipiente, no Brasil, as empresas industriais começam a mudar sua abordagem das questões ambientais, substituindo a postura reativa por uma abordagem estratégica e proativa. Essa é uma tendência internacional que tem sido pesquisada na literatura sobre as relações entre empresa e meio ambiente, em seus aspectos econômicos, ambientais e gerenciais (MILES \& COVIN, 2000; SHARMA, 2000). Nesse tipo de estratégia, a empresa coloca a questão ambiental como uma meta de ação legítima em seus negócios. Além disso, os investimentos ambientais são vistos como fonte de diferenciação e de obtenção de vantagens competitivas, tais como melhoria da imagem corporativa, diferenciação de produtos, redução de custos, melhoria na produtividade e inovação através da reengenharia de vários processos operacionais e de gestão.

No Brasil, um dos setores onde se encontram experiências desse tipo é o de higiene pessoal, perfumaria e cosméticos. Uma tendência emergente nessa indústria, e que constitui objeto de investigação deste estudo, é a de que algumas empresas brasileiras vêm incorporando ativos da biodiversidade amazônica como matériaprima de seus produtos. Isso ocorre como resposta à concorrência cada vez mais acirrada no setor, sobretudo em relação às empresas multinacionais, apontando a necessidade de se investigar como conseguir vantagens competitivas baseadas na inovação. Entretanto, as empresas que buscam internalizar de maneira sustentável esses ativos nas suas estratégias de inovação são levadas a diversificar e implementar funções no gerenciamento desse processo, atentando para:

- a capacidade de fornecer esse tipo de produto sistematicamente e com qualidade;

- o desenvolvimento e a capacitação de fornecedores para adquirir ativos da Amazônia;

- a necessidade de criar e incorporar novas competências na pesquisa e desenvolvimento;

- a busca de parcerias tecnológicas e

- a ampliação de competências a elas associadas.

Diante do exposto, este estudo tem como objetivo explorar o caso de uma empresa brasileira do setor de cosméticos, a Natura. A empresa adota uma estratégia que chamamos de "sustentabilidade proativa", haja vista que concebeu e implementou uma linha de produtos e marcas de cosméticos baseados na descoberta, desenvolvimento e utilização de extratos de plantas da Amazônia, cuja coleta é feita por comunidades locais, contribuindo para o desenvolvimento sustentável da região.

A estrutura deste artigo resulta da pesquisa para o doutorado da autora Anapatrícia Morales Vilha, realizada a partir da coleta de dados secundários sobre a empresa e o setor à que esta pertence. Houve igualmente a coleta de dados primários, obtidos durante entrevistas realizadas em agosto e setembro de 2004, com profissionais da Natura das áreas de pesquisa e desenvolvimento, de assuntos estratégicos e de marketing. A partir de um roteiro semi-estruturado, essas entrevistas trataram do gerenciamento da inovação da empresa baseado em tecnologias e produtos sustentáveis, especialmente das rotinas ligadas:

- aos arranjos estratégicos e estruturais; 
- ao relacionamento com os fornecedores e a capacitação destes;

- às competências tecnológicas e fontes de conhecimento;

- ao desenvolvimento de produtos e projetos de pesquisa e desenvolvimento; e

- à estratégia mercadológica e de apoio no mercado.

\section{Desenvolvimento sustentável e gestão da inovação}

Esta seção aborda os conceitos e princípios do desenvolvimento sustentável e a importância da sua assimilação pelas empresas, seja pela interferência sobre o produto, pela sua acepção mercadológica, pela construção de novos padrões de consumo ou, ainda, pela relação com a imagem da empresa no mercado. Também discute como saber gerir a capacidade de inovar viabiliza a inovação no mercado. Trata-se, portanto, de analisar a importância do processo de gerenciamento da inovação, de uma perspectiva integrada e dinâmica, visando a sua implantação.

\subsection{Desenvolvimento sustentável: conceitos, princípios e sua internalização pelas empresas}

Não existe uma definição conclusiva para desenvolvimento sustentável. Há quem confunda seus princípios com os de sustentabilidade ecológica. ${ }^{1}$ A definição mais conhecida foi a estabelecida em 1983 pela Comissão Mundial sobre Meio Ambiente e Desenvolvimento (CMMAD), também chamada de Comissão de Brundtland. ${ }^{2}$ Criada para realizar audiências ao redor do mundo e produzir um relatório formal - publicado três anos depois, com o título de Nosso Futuro Comum -, definiu desenvolvimento sustentável como "o desenvolvimento que atende às necessidades do presente sem comprometer a possibilidade das futuras gerações atenderem suas próprias necessidades" (COMISSÃO MUNDIAL SOBRE MEIO AMBIENTE E DESENVOLVIMENTO, 1991).

Dessa perspectiva, alcançar a sustentabilidade implica desfazer a ligação histórica entre crescimento econômico e aumento proporcional do consumo de recursos naturais e da poluição. Na verdade, a biosfera é, ao mesmo tempo, fonte dos recursos necessários à satisfação das necessidades humanas e o depósito dos desperdícios, fato que ressalta a importância do meio ambiente no paradigma do desenvolvimento sustentável. Contudo, vale mencionar que o desenvolvimento sustentável busca o crescimento econômico, com a difusão dos benefícios desse crescimento entre a população, e a preservação do meio ambiente, e que não precisa nem deve se restringir a uma preocupação com a sustentabilidade por um prisma puramente ambiental (GOMES, 1995).

Para Gomes (1995), o Relatório de Brundtland apresenta algumas premissas utópicas, sobretudo, quando estabelece a idéia do atendimento das necessidades humanas, com aumento do potencial de produção e garantia de mesmas oportunidades para todos. Evidentemente, discurso e prática podem ser, e são, diferentes, o que não elimina a importância do conceito e a necessidade de perseguir sua aplicação, seja qual for a abrangência do modelo.

Apesar das imprecisões, a discussão sobre o desenvolvimento sustentável evidencia uma nova racionalidade que envolve o crescimento econômico, meio ambiente e eqüidade social (BARONI, 1992). Além disso, é preciso reconhecer que o desenvolvimento sustentável não tem um padrão absoluto único, e que isso pode variar de acordo com a sociedade ou o setor industrial no qual o conceito está sendo aplicado.

Muitos empregam essa expressão com o sentido de existência de condições ecológicas necessárias à vida humana e ao bem-estar das gerações futuras. Isso é sustentabilidade ecológica e não desenvolvimento sustentável (LÉLÉ, 1991).

2 Esse título é uma homenagem à primeira-ministra da Noruega, Grö Harlen Brundtland, que presidiu a reunião que resultou no referido relatório. 
A crescente abrangência dos valores de sustentabilidade, demonstrada por maiores investimentos do setor empresarial, é resultado do processo de conscientização da sociedade a respeito da questão ambiental (FARIA, 2000), pois cada vez mais, existe o entendimento da sua importância e de que se trata de um assunto que diz respeito a todos. O marketing societal ${ }^{3}$, expresso por ferramentas de mídia, tem um papel muito importante no estabelecimento e na consolidação de um novo conjunto de valores e demandas, consoantes com padrões de consumo associados aos produtos "ambientalmente corretos" (CORAZZA, 1996).

Além de gerar novas oportunidades de negócios, a questão ambiental propicia o surgimento de inovações tecnológicas importantes, também chamadas de inovações ambientais ou "eco-inovações" (DAROIT \& NASCIMENTO, 2000). Por sua vez, a produção de eco-inovações requer um acúmulo de conhecimentos sobre o mercado e pesquisas científicas que permitam o desenvolvimento de soluções ambientais que tragam vantagem competitiva. Podem ocorrer desde pequenas melhorias nas atividades de rotina até grandes modificações de produtos e processos para se atingir as metas da organização. Dessa forma, oportunidades podem surgir para aqueles que desde já pensam e agem levando em conta a questão ambiental. De antemão, podem ser vislumbradas as seguintes possibilidades (LEMOS \& NASCIMENTO, 1998):

- os ecoprodutos, produtos verdes ou ambientalmente corretos começam a surgir com força, sinalizando o nascimento de um novo paradigma de consumo. Em 1990, o mercado mundial do ecobusiness movimentou cerca de US\$ 255 bilhões e absorveu 1\% do total da mão-de-obra nos países desenvolvidos (HIGGINS, 1994; SEBRAE et al., 1996);

- as exportações do ecobusiness respondem por cerca de 5\% a $10 \%$ da produção dos países desenvolvidos (SEBRAE et al, 1996);

- o vetor de crescimento do mercado de ecobusiness é a elevação do grau de consciência ambiental da população (SEBRAE et al, 1996);

- o market-based environmentalism (MBE) ou "mercado baseado no ambientalismo" é um paradigma emergente. Ele desafia a visão ortodoxa de que objetivos ecológicos e objetivos de mercado são incompatíveis. Relacionamentos cooperativos, tais como as "alianças verdes" e as regulamentações economicamente amigáveis (economically friendly) são fenômenos novos que, todavia, podem ser implementados estrategicamente pelas empresas (HARTMAN \& STAFFORD, 1997).

Recente pesquisa sobre gerenciamento estratégico ${ }^{4}$ observou que os temas ambientais influenciam cada vez mais a definição de estratégias comerciais e mercadológicas, como resultado de uma maior conscientização e expectativa dos consumidores quanto aos produtos ambientalmente mais corretos. Isso revela a importância das questões ligadas à reputação e imagem da empresa associadas à ética e à responsabilidade social (VINHA, 2002). Por sua vez, a reputação corporativa caracterizada por seus valores quanto ao desenvolvimento sustentável no mercado pode ser entendida como um ativo estratégico valioso na busca da vantagem competitiva, desde que seja articulado e apresentado de maneira diferenciada ou complexa. Isso significa que esse recurso, transformado por capacidades inovadoras, deve oferecer valor e ser raro, inimitável, insubstituível e intransferível para sustentar vantagens competitivas (HART, 1995; DIERICKX \& COOL, 1989).

Nesse contexto, a política de desenvolvimento sustentável pode induzir resultados diferenciados, por estar associada a fatores endógenos à empresa (como a possibilidade desta transformar esses valores, entendidos como recursos, em capacidade de inovação) e exógenos (relacionados à intensidade de aceitação

3 Marketing societal pode ser entendido como "a tarefa de determinar as necessidades, os desejos e os interesses dos mercados-alvo e fornecer as satisfações desejadas mais eficazmente do que a concorrência, de uma maneira que preserve ou melhore o bem-estar do consumidor e da sociedade" (KOTLER, 2000).

4 Pesquisa intitulada Meeting Changing Expectations, realizada em 1998 e divulgada no I Fórum Internacional do World Business for Sustainable Development (WBCSD), em Genebra, na Suíça, em março de 1999. 
mercadológica). Como esses recursos e a capacidade de inovação não estão disponíveis como uma "mercadoria" a ser adquirida, devem ser criados pela empresa. É a partir dessa perspectiva de criação que a empresa pode se diferenciar, criando heterogeneidade entre a concorrência (VINHA, 2002).

\subsection{A construção e o posicionamento de marcas no mercado e sua interface com causas sociais e ambientais}

As empresas estão constantemente tentando diferenciar sua oferta e reforçar sua marca no mercado. A construção de uma marca pode ser caracterizada como um dos pontos mais críticos na estratégia mercadológica para colocar um produto no mercado. Quando se cria uma marca, o desafio é o de desenvolver associações positivas a seu respeito. Nesse sentido, há consenso entre as empresas quanto ao reconhecimento de que a marca deve ter um papel maior do que identificar um produto e distingui-lo dos concorrentes. A marca deve ter uma personalidade (KOTLER, 2000).

O posicionamento de uma marca define a imagem da empresa diante de seus consumidores. Segundo Kotler (2000), "o posicionamento não é o que você faz com o produto e sim o que se faz com a mente do seu consumidor". Assim, o posicionamento de uma marca no mercado pressupõe uma vantagem diferencial criada com base em qualquer aspecto forte que possa ser oferecido pela empresa em relação à concorrência (HOOLEY, 2001).

Em termos de estratégia mercadológica, não é nenhuma novidade a construção de marcas e o posicionamento nos mercados associados a valores que num primeiro momento voltavam-se mais para características racionais, como performance e qualidade, passando posteriormente ao uso de valores emocionais, como amizade e confiança. Recentemente, contudo, as estratégias de construção de marcas e de posicionamento estão contemplando cada vez mais a associação com valores vinculados a causas sociais e ambientais (PRINGLE \& THOMPSON, 2000).

Para Pringle \& Thompson (2000), dessa perspectiva de estratégia de construção de marcas e de posicionamento no mercado, não basta que os consumidores saibam o que um produto ou serviço faz, ou que imagens ele transmite ao comprador. Eles precisam saber "em que" a empresa produtora dos produtos "acredita" e que ações ela "promove" em torno dessas causas. Nesse contexto, cresce o número de empresas que ao criarem uma marca, recorrem a ações sociais e ambientais.

\subsection{Marco conceitual sobre competências de gerenciamento da inovação}

O esforço para estabelecer e implementar estratégias de inovação decorre da busca por diferenciações que tragam vantagens competitivas. Ao analisarem o uso da tecnologia, de uma perspectiva concorrencial portanto, no contexto do ambiente externo à empresa -, estudiosos de estratégia competitiva como Michael Porter investigam o uso da tecnologia associado às cinco forças que levam à competição industrial. A partir daí, dentre "estratégias genéricas", escolhem aquela que pode ser usada pela empresa (TIDD et al., 2001). ${ }^{5}$ Para Tidd et al. (2001), a força dessa abordagem está no entendimento do ambiente competitivo no qual a empresa opera. Contudo, essa abordagem não trata dos aspectos tecnológicos e organizacionais no interior da empresa; isto é, nesse contexto, pouco importa a relação entre recursos/capacidades da empresa e a escolha estratégica. Além disso, esse enfoque não considera as implicações do tamanho da empresa nas estratégias tecnológicas, a influência da natureza do produto e de seus consumidores na escolha entre custo/diferenciação dos produtos/serviços e os possíveis benefícios das "relações adversas" entre compradores e fornecedores.

Entretanto, essas duas abordagens não são excludentes e sim complementares, dado que refletem fatores distintos que influenciam a dimensão da estratégia de inovação. Portanto, é necessário não só analisar o

Para Porter (1986), a intensa competitividade faz com que as empresas de um determinado setor industrial estejam atentas a um ambiente caracterizado pela rivalidade, pelo surgimento de novos concorrentes, pela lançamento de produtos substitutos e pelo crescente poder de barganha dos compradores e dos fornecedores. O objetivo é estudar a ação concorrencial, buscando vantagens competitivas através de estratégias genéricas, como baixo custo e diferenciação. 
ambiente competitivo que cerca a empresa, mas também buscar conhecimentos sobre como gerenciar recursos e a capacidade da empresa para a inovação no contexto de estratégias com esse objetivo. Kline \& Rosenberg (1986) também caracterizam essa realidade, ao identificarem que a inovação é resultado da interação entre as oportunidades de mercado e a base de conhecimentos e capacitações da empresa.

A prioridade atribuída aos recursos e capacidades da empresa na formulação de estratégias de inovação não é um fato novo. Em 1959, a economista Edith Penrose já preconizava um dos mais importantes estudos sobre o tema, The Theory of the Growth of the Firm. Não obstante, estudos mais recentes sinalizam a importância dos recursos e capacidades na condução de boas performances das empresas (PISANO \& TEECE, 1998; DURAND, 1999). Em todos os estudos mencionados, os recursos e as capacidades internas da empresa são elementos-chave para gerar competências tecnológicas e inovar com sucesso.

Para Dodgson (2000), "recursos" são todos os ativos e funções disponíveis para uma empresa, compreendendo: pesquisa e desenvolvimento, fábricas e instalações, ativos financeiros, recursos humanos, redes às quais as empresas pertencem e rotinas seguidas por estas através de sua atuação e práticas organizacionais. No entanto, eles são considerados conceitos estáticos, atribuindo-se às "capacidades inovativas" da empresa a tarefa de processar/gerenciar (dinamizar) esses recursos que, por sua vez, incluem uma série de atividades para gerar mudanças nas tecnologias e nos mercados. Dessa perspectiva, o gerenciamento dos recursos e das capacidades inovativas conduz à competência para competir. Esses ativos agregam valor, pois capacitam a empresa para explorar oportunidades e/ou neutralizar ameaças ambientais. São eles:

- os raros: visto que um número muito pequeno de empresas dispõem desse tipo de ativo para que haja uma efetiva competição na indústria;

- os inimitáveis: por causa de sua complexidade ou da singularidade das condições nas quais são adquiridos.

- os insubstituíveis e intransferíveis: pois não há formas alternativas de atingir os mesmos resultados.

Vale ressaltar que o gerenciamento dos recursos e das capacidades para a inovação que induzem a "competências competitivas" é de difícil imitação e transferência, por serem estabelecidos nos arranjos e complementaridades dos processos e rotinas organizacionais das empresas, com forte natureza tácita e de difícil replicação. As atividades que caracterizam as capacidades de inovação são (DODGSON, 2000):

\subsubsection{Previsão e avaliação}

Identificar o desenvolvimento tecnológico futuro é um exercício especulativo que gera cenários nas áreas de ciência e tecnologia, sinalizando trajetórias que provavelmente possam ser seguidas pelas empresas. A avaliação do contexto em que a empresa opera inclui o sistema nacional de inovação e as relações e impactos sobre as outras empresas. Cada vez mais estas procuram adotar esse procedimento, quando tentam se habilitar para o entendimento das oportunidades potenciais e dos desafios da ciência e da tecnologia.

\subsubsection{Busca e seleção}

A capacidade de inovação envolve a busca e a seleção de tecnologias que poderão garantir mais adiante, base para a competitividade. Essa tarefa é influenciada pelo volume de conhecimento acumulado pelas empresas.

\subsubsection{Aquisição e proteção}

Atividade relacionada às fontes de aquisição de novos recursos tecnológicos para as empresas por meio de pesquisa e desenvolvimento, licenças, alianças e compra direta.

\subsubsection{Implementação}

A capacidade de inovação está condicionada a que efetivamente ocorre a inovação tecnológica. Nesse sentido, o desenvolvimento de um plano tecnológico ajuda a visualizar prioridades de negócios, quando avalia a capacidade de pesquisa e desenvolvimento da organização, as necessidades imediatas e estratégicas da empresa a que a atividade de pesquisa e desenvolvimento pode ou não servir, além do potencial técnico e empresarial 
futuro de várias tecnologias. Pisano \& Teece (1998) mostram que essa atividade é também acompanhada de um número de "ativos complementares" exigidos para a comercialização, como capacidade competitiva de manufatura, vendas, marketing, distribuição e serviços.

\subsubsection{Coordenação e integração}

A habilidade de coordenar e integrar todas as funções da empresa em torno de suas atividades e prioridades tecnológicas é a tônica dessa atividade, podendo ser organizada pelo gerenciamento estratégico do portfólio tecnológico da empresa.

\subsubsection{Alinhamento}

A última atividade que caracteriza a capacidade de inovação de uma empresa é a sua habilidade para alinhar tecnologia com estratégia de negócios. Algumas ferramentas têm auxiliado na orientação das atividades de pesquisa e desenvolvimento como fonte de oportunidades de negócios.

Embora a inovação seja cada vez mais vista como um poderoso modo de construir e sustentar vantagens competitivas - além de uma forma de fortalecer as empresas na defesa de suas posições estratégicas -, de maneira isolada, ela não é garantia de sucesso. Assim, a inovação também depende da maneira como todo esse processo é conduzido; ou seja, seu desempenho depende de um gerenciamento estratégico (TIDD et al., 2001). Assim, o gerenciamento da inovação busca promover a capacidade de definir estratégias de inovação, por meio de processos decisórios abrangentes de seleção de apostas em novas tecnologias, produtos e processos, adequados aos recursos da organização (QUADROS, 2003).

De acordo com Tidd et al. (2001), pesquisas sobre inovação nas empresas têm sido realizadas durante mais de 50 anos, sob diversos ângulos. Grande parte dessas pesquisas converge para dois pontos-chave:

- o de que a inovação é um processo e não um evento isolado, devendo ser gerenciada de maneira dinâmica e integrada; e

- o de que a inovação pode ser conduzida de modo relativamente estruturado, em que seria feito um check list de rotinas (ou fases) para provê-la.

Tidd et al. (2001) sugerem, de modo bastante convergente com a abordagem de capacidades de Dodgson (2000) que é comum a organização ter de gerenciar quatro fases (cada uma com rotinas específicas) no processo de inovação:

- fase 1: prospecção - envolve monitorar e detectar seu ambiente (interno e externo), para escolher e processar sinais sobre mudanças potenciais;

- fase 2: seleção estratégica - busca escolher dentre as opções potenciais, aquela que apresenta os melhores sinais tecnológicos e de mercado, em consonância com os recursos e capacidades da empresa;

- fase 3: mobilização de conhecimento e competências - nesse momento convém avaliar os recursos, a capacidade que a empresa já dispõe e a que precisar ter, além do desafio de determinar como esses recursos podem ser utilizados de maneira estratégica;

- fase 4: implementação- significa colocar em prática o projeto de inovação, decorrente de vários estágios do desenvolvimento das idéias e do conceito, até o lançamento final do produto ou serviço. 


\section{Novas competências e práticas de gestão da inovação demandadas por uma estratégia de desenvolvimento sustentável: o caso da Natura}

\subsection{Breve caracterização do setor de higiene pessoal, perfumaria e cosméticos brasileiro}

No Brasil, o setor de higiene pessoal, perfumaria e cosméticos é avaliado em US\$ 6,339 bilhões, responde por $4 \%$ do consumo global desses produtos e coloca o país como o $7^{\circ}$ maior mercado mundial (UNICAMP-IENEIT, 2002). O setor reúne 1.123 empresas (15 delas de grande porte - que apresentam um faturamento líquido acima dos R $\$ 100$ milhões e representam 73,4\% do faturamento total do setor - ASSOCIAÇÃO BRASILEIRA DA INDÚSTRIA DE HIGIENE PESSOAL, PERFUMARIA E COSMÉTICOS, 2004). Nesse setor existe uma grande heterogeneidade de empresas. Nele atuam empresas internacionais de grande porte e com muitos recursos e empresas nacionais, muitas das quais de pequeno e médio porte (UNICAMP-IE-NEIT, 2002). Muitas dessas empresas nacionais fazem apenas a mistura dos componentes dos produtos finais, não atuando em todos os níveis da produção.

Quanto às multinacionais, elas são maioria entre as empresas de grande porte, e muitas são originárias dos setores farmacêutico e alimentício. Essas empresas tiram proveito da economia de escala e de escopo pelo fato de desenvolverem atividades correlatas, e também do fato de atuarem em segmentos diversificados. É o caso das americanas Johnson \& Johnson, Colgate-Palmolive, Procter \& Gamble e da anglo-holandesa Unilever. Apesar disso, existem também empresas multinacionais com atuação preponderantemente concentrada nos segmentos de perfumaria e cosméticos, como L'Oreal, Shiseido, Estee Lauder, Revlon, Coty, Avon, Mary Kay e Nu Skin.

Boa parte das multinacionais tem interesse no Brasil por ser um grande mercado consumidor (segmentos de mercado de massa) ${ }^{6}$ e por causa da possibilidade de atender outros mercados a partir de uma base brasileira, $o$ que garante uma posição estratégica muito relevante (VIEIRA, 2003). Chama a atenção também o fato de que essas empresas não arcam com gastos significativos para desenvolver novos produtos, nem capacidade produtiva inovadora local, limitando-se, em grande parte, à adaptação de tecnologia importada. Especificidades brasileiras e preferências de consumo locais poderiam ser fatores motivadores, ao menos, de esforços de adaptação de produtos "globais" ao mercado local, o que não ocorre. Pela grande possibilidade de realizarem transferência tecnológica, essas empresas acabam pouco colaborando para a promoção da capacidade tecnológica do país (VIEIRA, 2003).

A presença de grandes empresas internacionais, diversificadas e especializadas no setor contrasta com um grande número de pequenas e médias empresas nacionais com atuação focada na produção de perfumes e cosméticos. Dessas empresas, se destacam como grandes organizações a Natura e a Boticário, que atuam juntamente com um grande número de pequenas e médias empresas, como a Ox Marrow, Valmari, Vita Derm, Juruá, Payot, Pharmaervas, Chamma da Amazônia, Niasi, Leite de Rosas, Água de Cheiro e Contém 1g, entre outras. Essas empresas não só atuam no setor de cosméticos, mas, geralmente, também produzem perfumes, artigos de higiene pessoal, produtos infantis e até sabão.

Uma tendência emergente nessa indústria e que é objeto da investigação deste estudo é o fato de que algumas empresas brasileiras vêm incorporando ativos da biodiversidade amazônica - extraídos de cascas, folhas, raízes, sementes ou frutos - como matérias-primas de seus lançamentos, em resposta à forte concorrência com as multinacionais. No entanto, essas empresas nacionais apresentam abordagens bastante distintas quanto ao

O segmento de higiene pessoal concentra as maiores empresas multinacionais e tem o maior faturamento do setor. Por envolver a fabricação de produtos geralmente baratos e relacionados a hábitos de consumo freqüentes, possibilita uma forte penetração no mercado. Sabonetes, cremes dentais, shampoos e condicionadores estão presentes em praticamente $95 \%$ dos lares brasileiros (VIEIRA, 2003). 
aproveitamento de ativos da biodiversidade, com implicações igualmente distintas em relação ao desenvolvimento sustentável.

A diferença mais importante é que existem empresas que incorporam em seus produtos o uso de matériasprimas naturais (aqui identificadas como "empresas naturais") - não sendo baseadas necessariamente em atividades organizadas, segundo o princípio da sustentabilidade -; e outras que são responsáveis por produtos ambiental e socialmente proativos (aqui chamadas de "empresas sustentáveis") ${ }^{7}$. Nesse contexto, empresas sustentáveis não apenas se apropriam dos ativos naturais empregados na formulação de seus produtos, mas também mobilizam uma série de instrumentos que garantem a preservação ambiental e a sustentabilidade na extração de matérias-primas. Além disso, o processo de internalização de maneira sustentável desses ativos nas estratégias de inovação tende a levar essas empresas a repensar seus recursos e capacidade de inovação, bem como o processo de gerenciamento da inovação, da perspectiva do desenvolvimento sustentável. No grupo das empresas entendidas aqui como "sustentáveis" se destaca a Natura, caso que será examinado adiante, segundo os princípios de gerenciamento dos recursos e das "capacidades inovativas" no processo de inovação de Dodgson (2000) e de Tidd et al. (2001).

\subsection{Arranjos estratégicos e estruturais para a inovação na Natura}

A Natura produz e comercializa cosméticos por venda direta, com um volume de negócios de cerca de R $\$ 2,6$ bilhões/ano. A empresa tem filiais no Chile, Peru, Argentina e Bolívia e conta com cerca de 2.700 colaboradores. No Brasil, seus principais concorrentes são Avon, Boticário, L'Oreal, e Johnson \& Johnson (NASCIMENTO, 2002).

Diante das transformações que o setor de cosméticos tem exigido, a Natura implementou em sua estratégia competitiva o desenvolvimento de produtos segundo os princípios do desenvolvimento sustentável. Assim, suas crenças e valores junto ao mercado foram marcados pelo slogan "Bem estar bem" e sustentados pelos seguintes objetivos (BORGER, 2001):

- preservação e conservação da biodiversidade global;

- melhoria dos processos operacionais segundo critérios de eco-eficiência;

- fabricação de produtos ambientalmente corretos (ou amigáveis);

- estímulo ao uso de embalagens recicláveis.

Dessa forma, para a cúpula da empresa: "A Natura será uma das líderes mundiais de seu mercado, diferenciando-se pela qualidade das relações que estabelece, por suas crenças e valores expressos de forma radical, por meio de produtos, serviços e comportamento empresarial que promovem a melhor relação consigo mesma, com a natureza e com todos que a cercam." (Entrevista na empresa).

No ano 2000, a Natura lançou a linha Ekos de produtos de higiene pessoal, perfumaria e cosméticos "sustentáveis". São produtos biodegradáveis, que se decompõem na natureza em até 28 dias. As embalagens são recicláveis, os frascos são de resina, com uma porcentagem de material reciclado, e há opção de refil para todos os produtos dessa linha.

Para criar essa linha de produtos a empresa não se apoiou em nenhuma norma ou padrão de certificação de qualidade externo (séries ISO e EQA). Segundo os entrevistados, não foi seguido um sistema preestabelecido de gerenciamento que se baseasse em indicadores específicos de excelência das práticas ambientais. Em vez disso, foi adotado um modelo de processos gerenciais e tecnológicos adequado às especificidades estratégicas da companhia.

Muitas dessas empresas se utilizam da marca "Amazônia", ou dos princípios da biodiversidade brasileira, simplesmente como uma ferramenta de marketing ou um meio de atrair consumidores. 


\subsection{Relacionamento e capacitação de fornecedores}

A especificidade do modelo de aplicação dos princípios do desenvolvimento sustentável pela Natura é revelada pelo estabelecimento de redes de capacitação e parceria com fornecedores como as empresas alemã Cognis (2004) e a inglesa Croda (2004) que, por sua vez, trabalham toda a extração dos ativos da flora brasileira sem prejudicar o equilíbrio ambiental e a biodiversidade. Os entrevistados revelaram que essas empresas se comprometem a não empregar mão-de-obra infantil e a preservar as tradições e o estilo de vida das comunidades da floresta amazônica de onde são provenientes esses ativos.

Para garantir que esses insumos sejam extraídos de forma sustentável, a Natura desenvolveu o Programa de Certificação de Ativos com os fornecedores, apoiado e monitorado por uma ONG (organização nãogovernamental) - a Imaflora ${ }^{8}$ (FAPESP, 2003). Esse programa é um trabalho de capacitação do processo de averiguação e conhecimento da cadeia de custódia dos ativos, e trata do acompanhamento do percurso da matéria-prima desde a sua extração até a chegada à empresa. O programa estabelece critérios ambientais e sociais e é composto, em síntese, pelas seguintes etapas:

- auditoria do local de origem dos ativos;

- elaboração de um plano de manejo dos ativos;

- avaliação do impacto ambiental e social;

- implantação do plano de manejo;

- obtenção de certificado; e

- monitoramento periódico.

\subsection{Competência tecnológica e fontes externas de conhecimento}

Para apoiar e expandir seus investimentos em produtos sustentáveis, a Natura também estabeleceu uma parceria com a Fundação de Amparo à Pesquisa do Estado de São Paulo (Fapesp), criando o Natura Campus, um programa destinado a pesquisadores de universidades e centros de pesquisa, cujo objetivo é:

- viabilizar a aplicação prática de pesquisas acadêmicas no ambiente empresarial;

- apoiar o desenvolvimento de pesquisas inovadoras vinculadas às universidades e/ou institutos de pesquisa;

- capacitar novos recursos humanos para a área de cosméticos e fitoterápicos; e

- aplicar o conhecimento gerado em projetos de inovação tecnológica e no desenvolvimento de produtos cosméticos e fitoterápicos da empresa (FAPESP, 2003).

O primeiro edital do Natural Campus foi lançado em março de 2003 e sua área de concentração para recebimento de propostas de trabalho dos pesquisadores foi a biodiversidade. O programa busca formar competência em ciência e tecnologia nas áreas de biodiversidade brasileira, biotecnologia, bioquímica celular, bioquímica da pele, desenvolvimento de ativos cosméticos, meio ambiente e embalagens. Segundo os entrevistados da empresa, em 2003/2004 foram selecionados 14 projetos de pesquisa e desenvolvimento que terão de ser executados em dois anos. A empresa lançará novos editais voltados para outras áreas de concentração. Além do esforço representado por esse programa, a Natura mantém um intercâmbio sistemático com centros de excelência no exterior, o que permite a seus pesquisadores ter contato permanente com os principais avanços nas áreas farmacêutica, química e bioquímica (NASCIMENTO, 2002).

8 Segundo um dos entrevistados da Natura, a Imaflora é uma certificadora que verifica se o processo de extração e manejo dos ativos é feito de maneira sustentável. Com o seu deferimento, uma empresa pode solicitar o selo da Forest Stewardship Council (FSC), entidade reconhecida mundialmente, já que a Imaflora é acreditada pelo FSC. 


\subsection{Desenvolvimento de produtos e projetos de P\&D}

A Natura possui um centro de pesquisa e desenvolvimento e de inovação de cosméticos anexo à sua unidade produtora de Cajamar, na Grande São Paulo, que responde pelo lançamento de cerca de 200 novos produtos/ano (DIRETÓRIO DE PESQUISA PRIVADA - FINEP, 2004). De acordo com os entrevistados da empresa, ela aplica 3,5\% de sua receita líquida na área de pesquisa e desenvolvimento, lançando um produto a cada dois dias. Para garantir essa proporcionalidade entre número de produtos e tempo de lançamento, os funcionários da área de $\mathrm{P} \& \mathrm{D}$ da empresa mantém parcerias e intercâmbio de conhecimento e tecnologia em cosméticos com centros de pesquisas e desenvolvimento no Brasil e na Europa (especialmente na França), além da comunidade científica, fornecedores e concorrência internacional. A partir daí, são selecionadas, integradas e aperfeiçoadas as opções tecnológicas mais adequadas ao perfil da empresa, que serão então aproveitadas no desenvolvimento de novos produtos, como representado na Figura 1.

\section{Figura 1}

Processo de desenvolvimento e aquisição de tecnologia

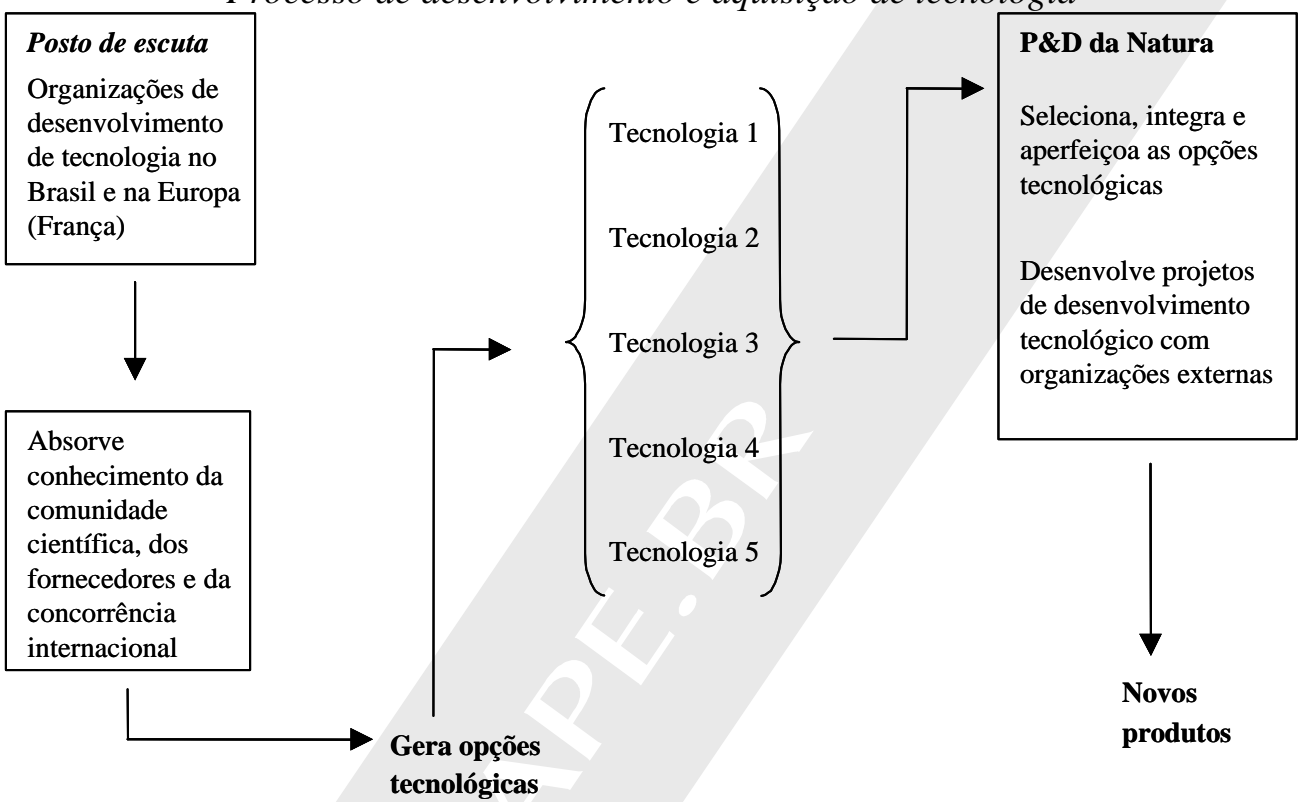

Fonte: Entrevistas na Natura, 2004

Ainda de acordo com os entrevistados, a empresa tem hoje 43 projetos na linha da biodiversidade. Metade do investimento de R \$62,3 milhões feito em 2003 em pesquisa e desenvolvimento foi para essa área, com expectativa de ampliar o perfil da carteira de produtos da empresa dentro dos princípios de sustentabilidade. Para internalizar princípios ativos da Amazônia como priprioca, andiroba, cumaru, copaíba, preciosa, breu-branco e murumuru, entre outros, no desenvolvimento de seus produtos sustentáveis, a empresa desenvolveu um processo de aquisição de tecnologia baseado em ativos da biodiversidade brasileira, estruturado do seguinte modo (Figura 2): 
Figura 2

Processo de aquisição de tecnologia baseado em ativos da biodiversidade brasileira

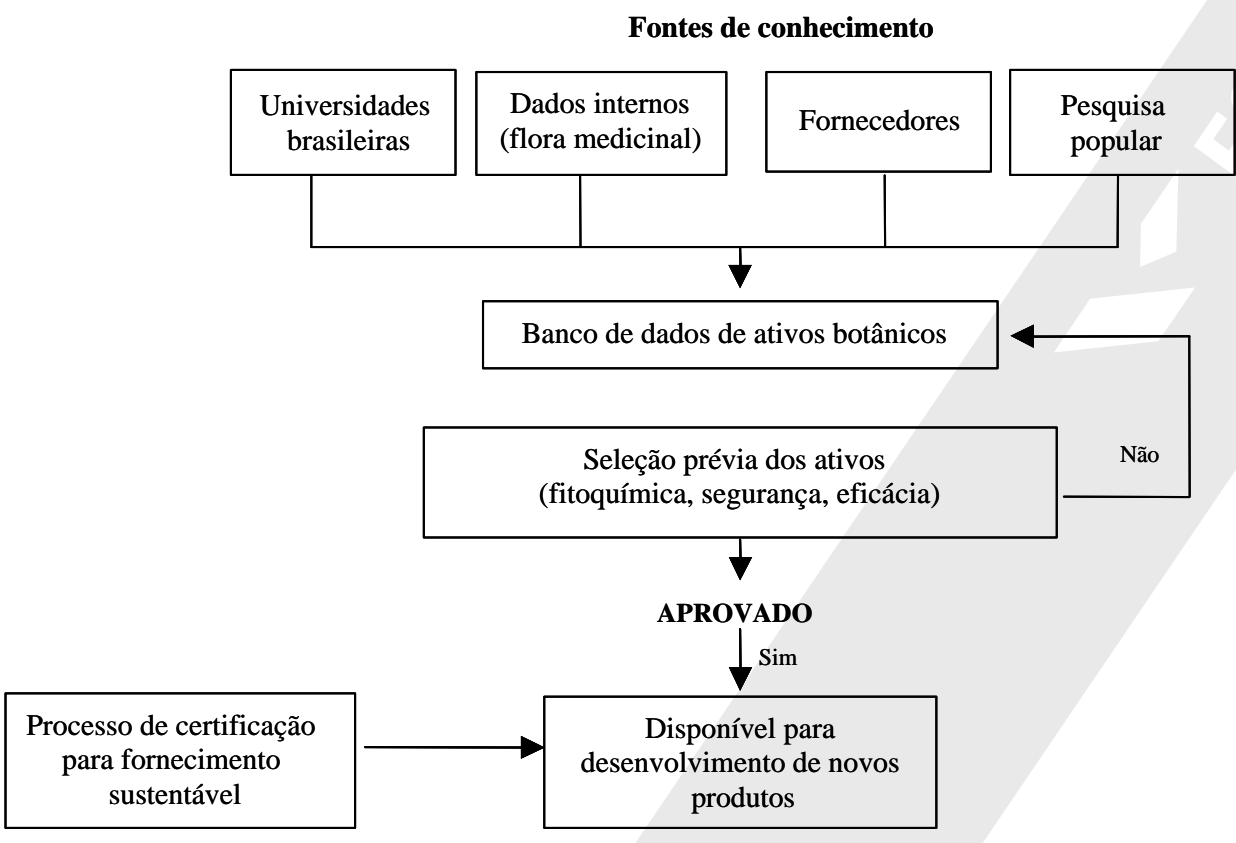

Fonte: Entrevistas na Natura, 2004.

\subsection{Ativos complementares para viabilização do processo de inovação no mercado}

Os entrevistados afirmaram que para reforçar no mercado a imagem de sustentabilidade social e ambiental da linha Ekos, a Natura estabeleceu um programa de treinamento e atualização da capacitação de suas consultoras (seu principal meio de interface com o mercado e instrumento-chave de promoção e vendas). Através de encontros, workshops, seminários e palestras, são abordados temas relacionados com responsabilidade social e educação ambiental, visando formar competências no processo de persuasão dos consumidores quanto à importância das práticas sustentáveis.

Todo esse esforço reforçou a imagem e o prestígio da empresa associados aos valores de sustentabilidade ambiental e social. Hoje, a Natura é reconhecida pelos concorrentes, consumidores e o público externo como uma "empresa brasileira socialmente responsável", e está entre as 10 empresas apontadas pelos Indicadores de Responsabilidade Social do Instituto Ethos (BORGER, 2001).9

Na entrevistas foi revelado que a linha Ekos é uma das mais bem-sucedidas da Natura. Para lançar essa nova linha, foram investidos $\mathrm{R} \$ 11$ milhões no desenvolvimento de produtos e esforços de marketing. Segundo entrevistados da empresa, no ano passado, as vendas dessa linha de produtos cresceram mais de $20 \%$, representando $10 \%$ do faturamento total da companhia. Em pouco mais de dois anos, a linha Ekos se transformou num negócio de cerca de $\mathrm{R} \$ 200$ milhões anuais, fato que estimulou outras empresas nacionais do setor a também desenvolverem iniciativas na região amazônica (WORLD BANK, 2003).

\footnotetext{
${ }^{9}$ Referência no Brasil, o Instituto Ethos é uma organização não-governamental composta por empresas de diversos setores, interessadas em desenvolver atividades de forma socialmente responsável.
} 


\section{Conclusão}

Com base nos princípios do desenvolvimento sustentável, a atuação da Natura demonstrou o potencial estratégico da empresa e sua percepção das oportunidades tecnológicas e de mercado para o desenvolvimento de produtos de maior valor agregado. Com preços premium, essa atuação explora nichos de mercado não ocupados pelas grandes empresas multinacionais e estabelece valores junto ao consumidor.

De um ponto de vista estratégico/mercadológico, devemos considerar que quando o consumidor adquire um produto desse setor, mais do que performance/qualidade, ele busca adquirir "sonhos", traduzidos por expectativas associadas à vaidade, um valor inerente ao ser humano. Estamos falando de orientação a um mercado sensível a valores e que, não necessariamente, envolve apenas a performance do produto, mas também o conceito que este promove. Com um modelo de negócios que incentiva a sustentabilidade, além de garantir a preservação ambiental na extração das matérias-primas, a Natura se diferencia por procurar garantir a manutenção econômica e social das comunidades onde são extraídos e manejados esses ativos. No entanto, sua orientação não está limitada à associação de sua imagem, reputação e marca aos princípios e práticas sustentáveis, mas também em promover a imagem de empresa que promove a sustentabilidade através do próprio conceito que seus produtos têm no mercado.

Diante do exposto, é razoável afirmar que a internalização dos princípios de sustentabilidade na empresa ganhasse um caráter estratégico em suas metas mercadológicas e tecnológicas, levando em conta:

- a seleção de oportunidades tecnológicas e mercadológicas e o estabelecimento de arranjos estruturais e estratégicos que possibilitassem a inovação pautada pelos princípios do desenvolvimento sustentável, criando processos gerenciais adequados à essas especificidades;

- a parceria com fornecedores ao sinalizar no processo de certificação de ativos a importância atribuída à capacitação de fornecedores, visando atender aos princípios de sustentabilidade, através da extração e manejo dos ativos ambientais junto às comunidades locais para composição dos produtos da linha Ekos;

- a competência tecnológica e a manutenção de fontes externas de conhecimento - através de parcerias com associações, entidades sociais, instituições de fomento à pesquisa e universidades -, objetivando não só apreender os movimentos e as tendências científicas e tecnológicas nas áreas de biodiversidade brasileira, biotecnologia, bioquímica celular, bioquímica da pele, desenvolvimento de ativos cosméticos, meio ambiente e de embalagens, mas também sedimentar know-how para constituir sua estratégia de inovação;

- criação de um centro de excelência em pesquisa e desenvolvimento de produtos, dedicando significativa parcela de seus recursos a projetos dessa área;

- promoção de esforços mercadológicos em ativos que viabilizem a inovação no mercado, levando o consumidor da Natura, cada vez mais, a vê-la como uma empresa ética, responsável e inovadora, que conseguiu transformar os princípios do desenvolvimento sustentável numa oportunidade de negócios viável e que atende ao consumo. 


\section{Referências bibliográficas}

ASSOCIAÇÃO BRASILEIRA DA INDÚSTRIA DE HIGIENE PESSOAL, PERFUMARIA E COSMÉTICOS. Apresenta o setor. Disponível em: <http://www.abihpec>. Acesso em: 20 out. 2004.

BARONI, M. Ambigüidades e deficiências do conceito de desenvolvimento sustentável. Revista de Administração de Empresas, São Paulo, v.32, n.2, p.14-24, abr./jun. 1992.

BORGER, F. G. Responsabilidade social: efeitos da atuação social na dinâmica empresarial. Dissertação (Mestrado) - Faculdade de Administração, Economia e Contabilidade da USP, 2001.

COGNIS. Apresentação institucional. Disponível em: <http://www. cognis.com> Acesso em:05 nov. 2004.

COMISSÃO MUNDIAL SOBRE MEIO AM BIENTE E DESENOVLVIM ENTO. Nosso futuro comum. Rio de Janeiro: Editora FGV, 1991.

CORAZZA, R. I. Inovação tecnológica e demandas ambientais: notas sobre o caso da indústria brasileira de papel e celulose. Dissertação (Mestrado) - Instituto de Geociências da Unicamp, Campinas, 1996.

CRODA. Apresentação institucional. Disponível em: <http://www. croda.com.br>Acesso em: 05 nov. 2004.

DAROIT, D.; NASCIMENTO, L. F. A busca da qualidade ambiental como incentivo à produção de inovações. In: ENCONTRO DA ANPAD, 24. 2000. Anais...

DIERICKX, I.; COOL, K. Asset stock accumulation and sustainability of competitive advantage. Management Science, [S.I.], v.35, p.15041513, Dec. 1989.

DIRETÓRIO DE PESQUISA PRIVADA (DPP) - Finep. Relatório setorial preliminar: setor de cosméticos. Finep: 2004. Disponível em: $<$ <ttp://www.finep.gov.br/PortalDPP> Acesso em: 05 out. 2004.

DODGSON, M. The management of technological innovation: an international and strategic approach. Oxford: Oxford University Press, 2000.

DURAND, R. The relative contributions of inimitable, non-transferable and non-substitutable resources to profitability and market performance. 1999 (mimeo).

FAPESP. Bons frutos do conhecimento. Revista Pesquisa Fapesp, n.86, p.19, abr. 2003.

FARIA, H. M. Benefícios econômicos da gestão ambiental: uma discussão. Dissertação (Mestrado) - Escola Federal de Engenharia de Itajubá (Efei), Minas Gerais, 2000.

GOMES, G. M. Desenvolvimento sustentável no nordeste brasileiro: uma interpretação impopular In: GOMES, G. M.; SOUZA, H. R.; MAGALHÃES, A. R. (Org.). Desenvolvimento sustentável no nordeste brasileiro. [S.I.]: Ipea, 1995. cap.6, p.9-60.

HART, Stuart. A natural-resource- based view of the firm. Academy of Management Review, [S.I.], v.20, n.4, p.986- 1014, Oct. 1995.

HARTM AN, C. L.; STAFFORD, E. R. Market-based environmentalism: developing green marketing strategies and relationships. American Marketing Association, p.156-163, Winter, 1997. In: LEMOS, A. D.; NASCIMENTO, L. F. A inovação limpa como geradora de inovação e competitividade. ENCONTRO DA ANPAD 22., 1998. Anais...

HIGGINS, J. Global Environmental Industry. Ecodecision, Jan. 1994 In: M AIM ON, Dália. Eco- Estratégia nas empresas brasileiras: Realidade ou Discurso? Revista de Administração de Empresas, São Paulo, v. 34, n. 4, p. 119-130, jul./ago., 1994.

HOOLEY, G. J. Estratégia de marketing e posicionamento competitivo. 2. ed. São Paulo: Prentice Hall, 2001.

KLINE, S. J.; ROSENBERG, N. An overview of innovation. In: LANDAU, R.; ROSENBERG, N. (Ed.). The positive sum strategy: harnessing technology for economic growth, Washington, D.C.: National Academy Press, 1986.

KOTLER, P. Administração de marketing: a edição do novo milênio.10. ed. São Paulo: Prentice Hall do Brasil, 2000.

LÉLÉ, S. M. Sustainable development: a critical review. World Development, v.19, n.6, p.607-621, June 1991.

LEMOS, A. D.; NASCIMENTO, L. F. A inovação limpa como geradora de inovação e competitividade. In: ENCONTRO DA ANPAD, $22 ., 1998$ Anais....

MILES, M. P.; COVIN, J. G. Environmental marketing: a source of reputational, competitive and financial advantage. Journal of Business Ethics. Dourdrecht, v.23, p.299-311, Feb. 2000.

NASCIMENTO, P. T. S. Embraer, Natura e Daimler Chysler do Brasil: três modos de gerir o desenvolvimento de produtos. In: ENCONTRO DA ANPAD, 26., 2002. Anais...

PISANO, G.; TEECE, D. The dynamic capabilities of firms: an introduction. In: DOSI, G.; TEECE, D.; CHYTRY, J. Technology, organization and competitiveness: perspectives on industrial and corporate change. Oxford: Oxford University, 1998.

PORTER, M. Estratégia competitiva: técnicas para análise de indústrias e da concorrência. 7. ed. Rio de Janeiro: Campus, 1986. 
PRINGLE, H.; THOMPSON, M. Marketing para causas sociais e a construção das marcas. São Paulo: Makron Books, 2000.

QUADROS, R. Padrões de gestão e estratégica da inovação tecnológica em empresas: a influência do tamanho, controle de capital e do setor. Projeto de pesquisa submetido ao CNPQ, Campinas, 2003.

ROBBINS, P. T. Greening the corporation: management strategy and the environmental challenge. London: Sterling VA, 2001.

SEBRAE / IBAMA / IHL / UNESCO / CNI / SESI / SENAI. Gestão ambiental: compromisso da empresa. Gazeta Mercantil, São Paulo, n.1-8, 1996. In: LEM OS, A. D.; NASCIM ENTO, L. F. A inovação limpa como geradora de inovação e competitividade. In: ENCONTRO DA ANPAD 22. 1998. Anais...

SHARMA, S. Managerial interpretations and organizational context as predictors of corporate choice of environmental strategy. In: Academy of Management Journal, Briarcliff Manor, v.43, p.681-697, Aug. 2000.

TIDD, J., BESSANT, J.; PAVITT, K. Managing innovation: integrating technological, market and organizational change. Wiley: Chichester, 2001.

UNICAMP-IE-NEIT. Estudo da competitividade de cadeias integradas no Brasil: impactos das zonas de livre comércio. Cadeia: cosméticos. Campinas: dez. 2002.

VIEIRA, S. P. 0 impacto da inovação na internacionalização da indústria: estudo baseado na experiência do setor brasileiro de cosméticos. Monografia de conclusão de curso - Instituto de Economia da Unicamp, Campinas, 2003.

VINHA, V. Stakeholder approach: novo paradigma operacional?. Instituto de Economia da UFRJ, 2002. Disponível em: <http// www.latec.uff.br/anais/Artigos/142.pdf >. Acesso em: 20 out. 2003.

WORLD BANK. Programa Piloto da Floresta Tropical Brasileira. Disponível em: <http://www.worldbank.org/rfpp/docs/SS3\%20port.pdf>. Acesso em: 1 out. 2003.

WORLD BUSINESS FOR SUSTAINABLE DEVELOPM ENT. M eeting changing expectations. Geneva: WBCSD Publ., Mar. 1999. 